\title{
Transactive Memory, Self-Construal and Subjective Well- Being in a Group of Indian Couples
}

\author{
Anjali Ghosh ${ }^{1}$ \\ Indian Statistical Institute, India.
}

\begin{abstract}
People in close relationships foster the development of shared memory schemas of each other. Their constellation of thoughts, feelings and actions shape their cognition, expression and experience of emotions. This shared mental model between the couples may lead to subjective well-being. The present study tries to explore the pattern of transactive memory system and self-construal in a group of urban Indian couples and how it relates to their subjective well-being. Transactive memory system was found to be the most significant predictor of subjective well-being. The results also reveal that the couple groups formed on the basis of different background variables did not differ significantly. But the pattern of relationships between the couple dyads was found to be strong for working wives group and couples having children. Future study with larger sample size from different regions of India with varied socio -economic and educational background will enhance understanding in this area.
\end{abstract}

Key words: Transactive memory, self-construal, subjective well-being, intimate relationsips

India is a culturally and linguistically diverse country where people of many religions, castes, creeds and tribes live together. But, they share some common beliefs, values and norms that help them to identify themselves as members of that society. Hofstede (2001) labeled India as a collectivist society where people from birth onwards are integrated into strong, cohesive in-groups, which continue to protect themselves throughout their lifetime. Collectivist values like interdependence; family integrity, security, obedience and conformity are given importance by the people of collectivist culture (Triandis, 1995). Though India has undergone modernization and urbanization in recent times and both collectivist and individualistic values are found to coexist in this

\footnotetext{
1 Associate Professor, Psychology Research Unit, Indian Statistical Institute, 203, B. T. Road, Kolkata, India - 700108. Email: anjali@isical.ac.in. Anjali Ghosh is currently Associate Professor at the Psychology Research Unit, Indian Statistical Institute, Calcutta, India. She received her Ph. D. in Psychology from the University of Calcutta and taught Psychology at the Patna University. Her research interests include social and cross-cultural Psychology, identity development, cognitive and moral development, self-efficacy and women studies.
} 
culture, yet the society has remained mainly traditional including family life and role structure.

\section{Relationship styles of Indian Couples}

The institution of marriage creates the basic social unit, the household and the centre of child rearing, mutual care and affection in India. People of India basically follow the arranged marriage system within their own religion, caste, social status and economic class. And through marriage two families come into mutual relationship. Though arranged marriages are still common in Indian societies but nowadays mainly in urban areas, people choose their own partner. But through the institution of marriage interpersonal relationships (usually intimate and sexual) are acknowledged by the society.

Interest in the perception, expectation, behavior, emotion and life satisfaction in intimate relationships are described in the works of poets, novelists, philosophers and scientists. Generally, Indian couples remain united and live with the partner throughout their lifetime, though divorce is not an uncommon feature now in urban India. As the number of educated urban women is increasing day by day and the aspiration for jobs are also rising, and at the same time the institution of marriage rather than cohabitation still prevail in India, there is a rise in the number of working couples in urban settings. More and more women are now working and at the same time continue to discharge their traditional domestic duties like household work and childcare. Many studies made comparisons between dual earner and single earner couples and found that it was not the wife's employment status rather attitudinal compatibility between the spouses determined marital adjustment and healthy relationship (Kapur, 1970; Ramu, 1987; Rani \& Khandelwal, 1992). It was observed that working wives with multiple roles experience more confidence in coping (Andrade, Postma \& Abraham, 1999) but need to strengthen their support network for their well-being (Rao, Apte \& Subbakrishna, 2003). It has also been observed that in Indian culture children are considered to be important for survival of lineage, fulfillment of the emotional needs of the parents and also for strengthening 
marital ties in different ecological settings (Baru \& Dhingra, 2004). However, differences or conflicts between the partners are observed with respect to attitudes to work and family roles.

In judging overall life satisfaction different people put emphasis on different aspects like, information sharing, personality make up, interest pattern, habit etc. Communication between the partners is an important issue for resolving many problems occurring during married life. But, when the couples face lack of proper communication, it becomes a major source of frustration and misunderstanding, and thus paves the way for breakups. Sen (2005) has pointed out that the perception of men and women about who is doing how much 'productive' work, or who is 'contributing' how much to the family's prosperity can be influential in narrowing the gap of inequality and can bring well-being to women vis-à-vis men. Sen (2005) went on to argue that the tradition of argumentation and disputation has been confined to the members of the male elite in India, but it is believed that discourse or communication between the couples can resolve many conflicting issues. And here lies the importance of the concept of "transactive memory", where the couple's knowledge of 'who knows what' or cognitive division of labor between the members specializing in different domains (Lewis, 2003) can lead to healthy relationship. Therefore, proper communication or transactive memory system between the partners i.e. to be cognizant about each other's knowledge may resolve many differences and may lead to well-being. In addition, how an individual's self-view (independent and interdependent self-construal) determines his/ her roles and relationships with others and how it brings satisfaction to one's life is an important question to be studied. In Indian culture no study is available regarding the relationship style of couples with respect to transactive memory and subjective well-being and how it operates through their self-construal process. The present study, therefore, attempts to explore this gap in research. 


\section{Transactive Memory}

Individuals in close relationships should be cognizant about others' knowledge, coordinate with each other regarding the function and information sharing, resolve differences among the members and finally try to reach at a solution. Couples in close relationships (for example, during their married life) have also to decide upon these things. They know many things about their partner's memories and also do not. Such knowledge about each other's memories takes time and practice to develop, but it is observed that close couples have an implicit structure for carrying out the pair's memory tasks.

The concept of transactive memory was first introduced by Wegner (1987) to explain behavior of couples in close relationships and he said that this transactive memory is greater than either of their individual memories. Transactive memory exists in the mind of an individual but transactive memory system exists between individuals as a function of their individual transactive memories. Wegner, Erber and Raymond (1991) mentioned that partners in intimate relationships cultivate one another as external memory aids and develop a "shared system for encoding, storing, and retrieving information" (p.923). The development of transactive memory system in a pair thus involves the communication and updating of information each has about the areas of the other's knowledge and this is more than one's individual memory. Each partner cultivates the other as an external memory aid (Engestrom, Brown, Engestrom \& Koistiman, 1990) and doing so becomes part of a larger system. Another way to update one's memory about partner's knowledge is through perceptions of the relative expertise of self and partner in different knowledge domains. These perceptions can be expected to develop through self-disclosure and in this way one's traits, past activities, emotions, preferences etc. are revealed.

Past researchers have compared memory processes of intimate couples with other dyads and found that cooperative cognitive systems do develop in dyads (Hollingshead, 1998, 2001; Wegner, Erber \& Raymond, 1991). Wegner et al. (1985) and Wegner (1987) observed that close relationships normally foster the development of shared memory 
schemas. Moreland and Myaskovsky (2000) proposed that specialization, credibility and coordination behaviors reflect the distributed, cooperative memory characteristic of transactive memory systems. Research on dating couples (Wegner, 1987) demonstrated that partners combined their respective expertise quickly and easily, thus suggesting an effective transactive memory system for smooth, efficient and coordinated functioning.

\section{Independent and Interdependent Self-Construal}

Individuals' constellation of thoughts, feelings and actions and the way the person defines oneself i.e. self-construal determine their roles and relationships with others and guide their behavior in different contexts. According to Markus and Kitayama (1991) selfconstrual may be either independent or interdependent. People with independent selfconstrual see the self as stable and separate from interpersonal context, and give importance to self-promotion, autonomy, assertiveness and uniqueness. On the other hand, people with interdependent self-construal see the self as more flexible and interwined with the social context, and give importance in maintaining group harmony and fitting in with others. Markus \& Kitayama (1991) argued that differences in selfconstrual lead to important differences in individual's psychological experience and suggested that self-construal shapes cognition (e.g. attention, cognitive elaboration and representation in memory), emotion (e.g. expression and experience of particular emotions), and motivation (e.g. for cognitive consistency and affiliation). Although people may have independent or interdependent aspects of self -construal but multiple modes of self -construal exist among all individuals in all cultures (e.g. Brewer \& Chen, 2007).

\section{Subjective Well-being}

It is observed that people in close relationships foster the development of shared memory schemas. It is interesting to know how transactive memory or shared cognition between the partners and the way one defines himself or herself during their married life 
influence their satisfaction with life and positive emotions which are components of subjective well -being.

Past researches have indicated that satisfaction with life is influenced by personality (Diener \& Lucas, 1999), and by culture (Diener \& Suh, 1999). Diener, Gohm, Suh \& Oishi (2000) observed similarity between marital status and subjective well being across the world and found that the benefit of marriage over cohabitation was greater in collectivist than in individualist nations. Diener \& Diener (1995) demonstrated that selfesteem is a stronger predictor of life satisfaction in individualistic cultures than in collectivistic cultures. Schimmack, Diener \& Oishi (2002) proposed a causal model of the relations between personality (Extraversion and Neuroticism) and the two components i. e. cognitive and affective components of subjective-well being. This model indicates that extraversion and neuroticism are more strongly related to the affective component of subjective-well being than to the cognitive component. They also found that in addition to hedonic balance, satisfaction with academic performance and romantic satisfaction etc. also predicted life satisfaction. Gove et al. (1990) suggested that marriage provides a strong positive sense of identity, self-worth and mastery. Williams (1988) also observed that interpersonal intimacy and emotional support provided by a spouse lead to well being. Study done on a large sample of married men and women in UK, Estonia and Finland indicated that life satisfaction is higher among women, married couples and those who have professional career (Schoon, Hansson \& Salmela-Aro, 2005).

But, most of these studies reflect the role of personality, self-esteem and cultural component as important factors of life satisfaction. The role of shared cognition or transactive memory system between the partners as an indicator of subjective well being is missing, especially in the Indian context. The present study, therefore, wants to investigate empirically how transactive memory system or shared cognition and independent and interdependent self-construal influence subjective well -being as measured in terms of life satisfaction and positive affect in a group of urban Indian couples. 
More specifically, the objectives of the study are:

- To explore the magnitude of relationship between the couple dyads with respect to different dimensions of transactive memory system (TMS), self-construal and subjective well-being.

- To explore the pattern of relationship of different dimensions of TMS and selfconstrual with the two components of subjective well-being and also to find out its predictive power.

- To find out the effect of different background variables for example, working status of couples, type of marriage, parenthood etc. on subjective well-being.

\section{Method}

\section{Participants}

Participants of this study were married couples living together in the city of Kolkata, India. Data were collected from 50 couples but due to some missing information the final sample size restricted to 46 couples $(\mathrm{N}=92)$. The mean age of the husband group was 47.4 years and for the wife it was 42.0 years. The mean years of married life for the group was found to be 16.0 years and all the couples had only one marriage. The educational background of the couples varied from high school to post graduation and above. The majority of the couples (89.2\%) came from middle socio-economic background. The group of husbands was working in different professions varying from teaching and research, medical, law, journalism, management, business to various government and private services. But in the wives group $56.6 \%$ were working in some profession (for example, teaching and research, medical, business and various other services) while the rest $43.4 \%$ were homemaker. $60.9 \%$ of the couples chose their partners on their own while 
$39.1 \%$ had arranged marriage. $58.7 \%$ of the couples had only one child, $26.1 \%$ had two children while $15.2 \%$ had no child.

\section{Instruments}

(a) Transactive Memory System (TMS): Transactive memory system is a concept of social cognition which refers to the idea that people in continuing close relationships develop a shared system for encoding, storing and retrieving information from different substantive domains. It is assumed that when a TMS exists between couples, it develops some specialized knowledge, credibility perception and coordination processes. To measure transactive memory system of couples one scale has been developed by the author based on the Transactive Memory Scale of Kyle Lewis (2003). The present scale has 12 items with 5-point Likert type scaling format ranging from strongly disagree (1) to strongly agree (5). After item analysis, two items were found to have low item -total correlations and they were dropped from the scale. The principal component factor analysis extracted three factors named as Factor I: Coordination (4 items, e.g., "We accomplish any task smoothly and efficiently"), Factor II: Credibility (3 items, e.g., "I am comfortable at accepting suggestions from my spouse at the time of any problem") and Factor III: Expertise (3 items, e.g., "Both of us have some specialized knowledge for running our home smoothly"). The total score indicates overall transactive memory system of the individual. The Cronbach's alpha reliability of the total scale was found to be .72

(b) Self-Construal Scale (SCS): Self-construal scale developed by Singelis (1994) was used in this study. This is a cross-culturally validated scale. The scale measures independent and interdependent dimensions of self-construal with the help of 15 items per dimension. Independent self-construal refers to that self who is stable and separate from interpersonal context and value self-promotion, autonomy, assertiveness and uniqueness. Interdependent self-construal, on the other hand, view the self as more flexible and interwined with the social context and give importance in maintaining group 
harmony. Respondents were asked to indicate their agreement with each of the items on a 7-point scale ranging from 1 (strongly disagree) to 7 (strongly agree). The Cronbach alpha reliability for the present sample was found to be .58 for the independent self-construal and .66 for the interdependent self-construal.

(c) Life Satisfaction Scale: The Satisfaction with Life Scale (SWLS) developed by Diener, Emmons, Larsen \& Griffin (1985) was used in this study. It is a five-item scale that assesses the cognitive component of subjective well-being and is widely used across different cultures around the globe. Respondents are asked to indicate the current status of their life satisfaction and self-defined expectations regarding what they would like their lives to be. The scale uses a 7-point response format ranging from strongly disagree (1) to strongly agree (7). The alpha coefficient of the scale for this group of participants was found to be .71 .

(d) Positive Affect Scale: Affective component of the subjective well-being was measured by a two-item scale specially designed for this study by the author. The scale measures perception of happiness and the role of spouse in making the partner happy. This is also a 7-point scale ranging from strongly disagree (1) to strongly agree (7). The alpha coefficient of the scale was found to be .79 .

(e) Demographic Information Schedule: Respondents' demographic information like age, gender, educational level, working status, socio-economic condition, type of marriage, years of married life, number of children etc., were collected with the help of a demographic information schedule.

\section{Procedure}

The purpose of the study was briefly introduced to the participants and then informed consent was taken from all the participants. After this, all the measures were administered to the couple dyads individually mentioning the confidentiality of the information. The measures were administered in English language, as all the participants were capable to respond in English. Some of the participants (8\%) did not give all the 
responses either due to their unwillingness to continue or for some other reasons and their responses were not considered for analysis.

\section{Results}

Relationship between the couple dyads with respect to different dimensions

Means and standard deviations (SD) for different variables for the couple dyads were calculated and correlation coefficients were computed as well for finding out the relationship between the couples with respect to different dimensions of TMS, self construal and subjective well -being (as measured through life satisfaction and positive affect). The results are shown in Table-1.

Table 1: Means, Standard Deviations (SD) and correlation coefficients between couples with respect to different variables

\begin{tabular}{clcccc}
\hline \multirow{2}{*}{ Variables } & \multicolumn{2}{c}{ Husband } & \multicolumn{2}{c}{ Wife } & H-W \\
\cline { 2 - 6 } & Mean & SD & Mean & SD & r-value \\
\hline TMS I & 16.00 & 2.27 & 14.56 & 2.70 & $.42^{* *}$ \\
TMS II & 11.76 & 1.85 & 11.80 & 2.33 & $.31^{*}$ \\
TMS III & 11.91 & 1.74 & 11.76 & 2.15 & .11 \\
TMS Total & 39.67 & 4.42 & 38.13 & 5.30 & $.42^{* *}$ \\
Ind SC & 5.05 & .57 & 4.99 & .59 & .28 \\
Interp SC & 5.19 & .58 & 5.16 & .42 & $.48^{* *}$ \\
LS & 23.30 & 5.72 & 22.89 & 5.30 & $.48^{* *}$ \\
PA & 11.30 & 2.39 & 10.63 & 2.56 & $.42^{* *}$ \\
\hline
\end{tabular}

Note: $\quad{ }^{*} \mathrm{p}<.05 \quad * * \mathrm{p}<.01$

TMSI= Coordination, TMS II= Credibility, TMS III= Expertise,

TMS Total $=$ Total score of Transactive Memory

Ind SC= Independent Self construal, Interp SC= Interdependent Self Construal, $\mathrm{LS}=$ Life satisfaction, $\mathrm{PA}=$ Positive Affect

It is clear from the above table that the couples scored more or less similarly in different dimensions of transactive memory system, independent and interdependent selfconstrual and also in the two components of subjective well-being. But the wife groups scored slightly lower than the husband group in almost all the dimensions. The r-values reported in the above table indicate positive relationship between the couples with respect 
to different dimensions of transactive memory system but this relationship was found to be strong for coordination, credibility and overall transactive memory system. High significant positive relationships were also obtained between the couple dyads for interdependent self-construal, life satisfaction and positive affect.

Pattern of Relationship and Predictive Power of TMS and Self-Construal with Subjective well-being

One of the objectives of this study is to find out the pattern of relationship of different dimensions of TMS and self-construal with the two components of subjective well - being. Hence, correlation coefficients were calculated for the couple dyads and the values are presented in Table-2

Table-2: Correlation coefficients of TMS and self-construal with subjective well being for couple dyads.

\begin{tabular}{ccccc}
\hline \multirow{2}{*}{ Dimensions } & \multicolumn{2}{c}{ Husband } & \multicolumn{2}{c}{ Wife } \\
& LS & PA & LS & $.60^{* *}$ \\
\hline TMS I & $.43^{* *}$ & $.47^{* *}$ & .16 & $.37^{*}$ \\
TMS II & $.36^{*}$ & $.33^{*}$ & $.36^{*}$ & $.48^{* *}$ \\
TMS III & .15 & .34 & $.52^{* *}$ & $.60^{* *}$ \\
TMS Total & $.43^{* *}$ & $.52^{* *}$ & $.37^{*}$ & .03 \\
Ind SC & .23 & .19 & .17 & -.04 \\
Interp SC & .23 & .19 & & \\
\hline
\end{tabular}

${ }^{*} \mathrm{p}<.05 \quad * * \mathrm{p}<.01$

The results reported in the above table indicate that the TMS is significantly and positively related with life satisfaction and positive affect for the couple dyads except for the expertise dimension of TMS for husbands and credibility for wives. The relationship of self -construal with cognitive component of subjective well-being was found to be positive but moderate. But almost no relationship was found to be observed for wives with affective component, which indicates that self -construal process does not play important role for their positive feelings. 
Next, multiple linear regression analyses were conducted separately for husbands and wives to know whether subjective well-being as measured in terms of life satisfaction and positive affect can be predicted by overall transactive memory system and selfconstrual of couples. The results are presented in Table-3.

Table -3: Results of Regression Analysis

\begin{tabular}{|c|c|c|c|c|c|c|c|c|}
\hline \multirow{3}{*}{ Predictors } & \multicolumn{4}{|c|}{ Husband } & \multicolumn{4}{|c|}{ Wife } \\
\hline & \multicolumn{2}{|c|}{ LS } & \multicolumn{2}{|c|}{ PA } & \multicolumn{2}{|c|}{ LS } & \multicolumn{2}{|r|}{ PA } \\
\hline & $\beta$ & $\mathrm{t}$ & $\beta$ & $t$ & $\beta$ & $\mathrm{t}$ & $\beta$ & $t$ \\
\hline TMS & .40 & $2.88^{* *}$ & .50 & $3.77^{* *}$ & .47 & $3.66^{* *}$ & .62 & $4.94^{* *}$ \\
\hline Independent SC & .06 & 0.42 & .01 & 0.07 & .27 & $2.00 *$ & -.06 & 0.48 \\
\hline Interdependent SC & .17 & 1.16 & .15 & 1.04 & .01 & 0.07 & -.08 & 0.62 \\
\hline
\end{tabular}

It is seen from the above table that both life satisfaction and positive affect i.e., subjective well-being of couples can be efficiently predicted by overall transactive memory system of couples. For husbands $23 \%$ of the variance can be efficiently predicted by TMS for explaining life satisfaction and 29\% for explaining positive affect. But in case of wives TMS as well as independent self-construal were found to be the significant predictors for life satisfaction. It can efficiently predict in $35 \%$ of the cases whereas positive affect was found to be predicted by TMS in $37 \%$ of the cases. This indicates that both cognitive and affective components of subjective well-being are dependent upon the shared cognition of couples.

\section{Effect of Background Variables}

The group of couples studied in the present investigation varied with respect to several background variables for example, working status of the couples, type of marriage (arranged or own selection), parenthood (number of children) etc. In the present sample, $56.6 \%$ of the wives were working in some professions while the rest $43.4 \%$ were 
homemaker. So, the total sample was first divided into four groups on the basis of working status: (a) Group I: Husbands having working wife, (b) Group II: Husbands having non-working wife, (c) Group III: Working wife, and (b) Group IV: Non-working wife, and then one- way ANOVA was conducted to see if there is any effect of working/ non-working status on the subjective well-being of couples. The F-values for both life satisfaction $(\mathrm{F}=0.40)$ and positive affect $(\mathrm{F}=2.02)$ were found to be insignificant, thereby suggesting that the groups as per working status do not differ significantly with respect to their subjective well-being. Similarly, no significant differences in subjective well-being among different groups of couples were observed with respect to type of marriage (arranged or own selection) and parenthood (no child, one child and more than one child). In addition, the study also explored how these groups of couple dyads segregated in terms of working status (working / non working), type of marriage and parenthood, are related with respect to different variables. Therefore, correlation coefficients were computed between the couple dyads with respect to TMS, independent and interdependent self- construal, life satisfaction and positive affect. The r-values are presented in Table-4. 
Table - 4: Correlations between couple dyads with respect to different dimensions based on background variables

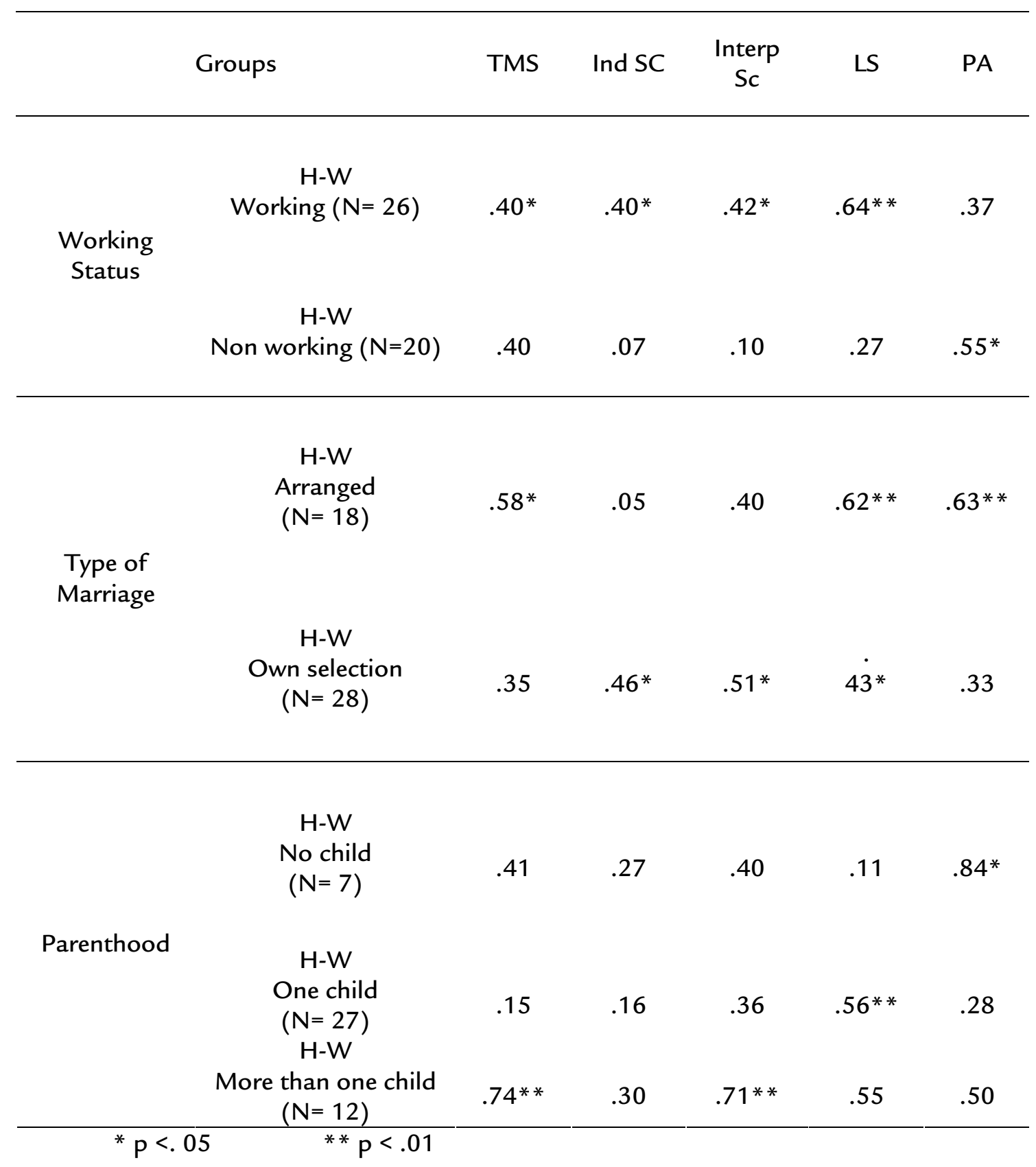

The correlation values indicate that there is strong relationship between the couples of working groups with respect to different dimensions. It shows that the transactive memory system, self-construal and subjective well-being of working group couples (both partners are working) are more similar than the group of couples where both partners are not working. Similarly, the couple dyads with own selection of partner 
and parenthood have moderate to strong relationship between themselves with respect to TMS, self-construal and subjective well -being.

\section{Discussion}

The present study explores the relationship styles of a group of urban Indian couples with respect to transactive memory system, self-construal and subjective wellbeing. The results reveal that the couple dyads are more or less similar in their constellation of thoughts, feelings and shared memory schemas, which have been reflected in their coordination for information processing, belief about the reliability of other member's knowledge and greater understanding about each other's areas of expertise. This result is consistent with the findings of Wegner (1987) who observed that couples in close relationships develop shared cognition which help them to work in efficient and coordinated way. The couples are also more or less similar in their patterns of cognitive and affective components of subjective well-being. One of the possible reasons for this may be that the couple dyads studied here came from more or less similar socio-cultural background, and majority of them came from well-educated middle class families.

The important thing revealed from this research is that overall transactive memory system was found to be the most significant predictor of subjective well being. This shows that coordinating and sharing information with the spouse and believing in other's expertise may give satisfaction to the partners both cognitively and affectively. This may have happened because the couples have lead their married life with only one partner for quite a long time (on an average for about 16 years). This supports the findings of Diener et al. (2000), Gove et al. (1990) and Williams (1988) who observed that marriage provides a sense of identity and subjective well being to the couples. Moreover, this is more applicable in a collectivist society like India, where family integration, interdependence and security are given importance and traditionally the Indian woman is expected to live in her husband's family after marriage. 
The role of independent self-construal was also found to be important for predicting cognitive component of subjective well-being in case of wives. This shows that women, especially the non-working women, who give importance to self-promotion, autonomy and uniqueness along with shared cognition with the spouse, experience greater life satisfaction cognitively.

The results also demonstrate that the couple groups formed on the basis of different background variables did not differ significantly. But the pattern of relationships between the couple dyads for transactive memory system and life satisfaction were found to be strong for working wives group, arranged marriage selection and couples having children. This shows that when the wives have some occupation in terms of earning, their life satisfaction is more or less similar cognitively with their partners. Similarly, parenthood in couples gives more life satisfaction cognitively. This may be due to the traditional collectivist values still prevailing in India which indicates that parenthood fulfills one's emotional needs, strengthens marital ties and is important for survival of lineage (Baru \&Dhingra, 2004). The present study also confirms this even done on a group of educated urban middle class couples. On the other hand, couples who chose their partners on their own are more like minded in terms of their self-view and cognitive component of subjective well-being. It can also be explained in terms of Sen's (2005) work that the perception of productive work and contribution to family's prosperity in Indian culture bring well-being to the lives of men and women.

Overall, the findings indicate that couples with shared mental model have credibility perception, coordinate with each other, share responsibilities and make joint decisions and at the same time while maintaining self -identity enjoy greater subjective well being. 


\section{Conclusion}

It can be concluded from the findings of the study that the couples studied here have more or less similar types of transactive memory, independent and interdependent self-construal and subjective well-being. The salient point coming out of this research is that transactive memory system is the most important indicator of subjective well being. That is, the couples in close relationships develop shared memory schemas through self disclosure and communication, engage in many conversations and make joint decisions which in turn is reflected in their subjective well-being. The findings of the study have significant implications. Transactive memory, an important indicator of subjective wellbeing, should be well developed in couples for healthy intimate relationships and life satisfaction through self-disclosure, communication, sharing of responsibilities and by making joint decisions.

\section{References}

Andrade, C., Postma, K. \& Abraham, K. (1999). Influence of women's work status on the well-being of Indian couples. International Journal of Social Psychiatry, 45(1), 65-75.

Baru, A. \& Dhingra, R. (2004). Personal and interpersonal dimensions of childlessness in three different ecological settings. Journal of Human Ecology, 15 (4), 289-294.

Brewer, M.B.\& Chen, Y. (2007). Where (who) are collectives in collectivism? Toward conceptual clarification of individualism and collectivism. Psychological Review, 114(1), 133-151.

Diener, E., \& Diener, M. (1995). Cross-cultural correlates of life satisfaction and selfesteem. Journal of Personality and Social Psychology, 68(4), 653-663.

Diener, E., Emmons, R.A., Larsen, R.J. \& Griffin, S. (1985). The satisfaction with Life scale. Journal of Personality Assessment, 49(1), 71-75. 
Diener, E., Gohm, C. L., Suh, E. \& Oishi, S. (2000). Similarity of the relations between marital status and subjective well-being across cultures. Journal of Cross Cultural Psychology, 31(4), 419-436.

Diener, E., \& Lucas, R.E. (1999). Personality and subjective well-being. In D. Kahneman, E. Diener, \& N. Schwarz (Eds.) Well-being: The Foundations of Hedonic Psychology (pp.213229). New York: Russell Sage Foundation.

Diener, E. \& Suh, E.M. (1999). National differences in subjective well-being. In D. Kahneman, E. Diener, \& N. Schwarz (Eds.) Well-being: The Foundations of Hedonic Psychology (pp.434-452). New York: Russell Sage Foundation.

Engestrom, Y., Brown, K., Engestrom, R. \& Koistinen, K. (1990). Organizational forgetting: An activity theoretical perspective. In D. Middleton \& D. Edwards (Eds.). Collective Remembering, (pp.137-168). Newbury Park, CA: Sage.

Gove, W.R., Style, C.B., \& Hughes, M. (1990). The effect of marriage on the well-being of adults: A theoretical analysis. Journal of Family Issues, 11(1), 4-35.

Hofstede, G. (2001). Culture's Consequences: International Differences in Work -related Values. Beverly Hills, CA: Sage.

Hollingshead, A.B. (1998). Retrieval processes in transactive memory systems. Journal of Personality and Social Psychology, 74(3), 659-671.

Hollingshead, A.B. (2001). Cognitive interdependence and convergent expectations in transactive memory. Journal of Personality and Social Psychology, 81(6), 1080-1089.

Kapur, P. (1970). Marriage and the Working Women in India. Delhi: Vikas Publications.

Lewis, K. (2003). Measuring transactive memory systems in the field: Scale development and validation. Journal of Applied Psychology, 88(4), 587-604.

Markus, H.R. \& Kitayama, S. (1991). Culture and the self: Implications for cognition, emotion and motivation. Psychological Review, 98(2), 224-253.

Moreland, R.L. \& Myaskovsky, L. (2000). Exploring the performance benefits of group training: Transactive memory or improved communication? Organizational Behaviour and Human Decision Processes, 82(1), 117-133. 
Ramu, G.N. (1987). Indian husbands: Their role perception and performance in single and dual-earner families, Journal of Marriage and the Family, 49(4), 903-915.

Rani, V. \& Khandelwal, P. (1992). Family environment and interpersonal behaviour: A comparative study of dual career and single career families. The Indian Journal of Social Work, LIII (2), 232-243.

Rao, K., Apte, M. \& Subbakrishna., D. K. (2003). Coping and subjective well-being in women with multiple roles, International Journal of Social Psychiatry, 49(3), 175-184.

Schimmack, U., Diener, E., \& Oishi, S. (2002). Life Satisfaction as a momentary judgment and a stable personality characteristic: The use of chronically accessible and stable sources. Journal of Personality, 70(3), 345-385.

Schoon, I., Hansson, L. \& Salmela-Aro, K. (2005). Combining work and family life: Life satisfaction among married and divorced men and women in Estonia, Finland, and the UK. European Psychologist, 10(4), 309-319.

Sen, A. (2005). The Argumentative Indian. London: Penguin Books Ltd.

Singelis, T.M. (1994). The measurement of independent and interdependent selfconstruals. Personality and Social Psychology Bulletin, 20(5), 580-591.

Triandis, H. C. (1995). Individualism and collectivism, Boulder, CO: Westview Press.

Wegner, D.M., Giuliano, T., \& Hertel, P. (1985). Cognitive interdependence in close relationships. In W.J. Ickes (Eds.) Compatible and Incompatible Relationships, (pp.253276). New York: Springer-Verlag.

Wegner, D.M. (1987). Transactive memory: A contemporary analysis of the group mind. In B. Mullen \& G.R. Goethals (Eds.) Theories of Group Behaviour (pp.185-208). New York: Springer-Verlag.

Wegner, D.M., Erber, R. \& Raymond, P. (1991). Transactive memory in close relationships. Journal of Personality and Social Psychology, 61(6), 923-929.

Williams, D.G. (1988). Gender, marriage, and psychosocial well-being. Journal of Family Issues, 9(4), 452-468. 
Received: March 31 $1^{\text {st }}, 2008$

First Revision Received: September $15^{\text {th }}, 2008$

Second Revision Received: October $5^{\text {th }}, 2008$

Accepted: October $5^{\text {th }}, 2008$ 